\title{
Parameter Identification for Salinity in a Quasilinear Thermodynamic System of Sea Ice
}

\author{
Wei Lv, ${ }^{1}$ Xiaojiao Li, ${ }^{1}$ and Enmin Feng ${ }^{2}$ \\ ${ }^{1}$ Department of Mathematics, Shanghai University, Shanghai 200444, China \\ ${ }^{2}$ School of Mathematical Sciences, Dalian University of Technology, Dalian 116024, China \\ Correspondence should be addressed to Wei Lv; lvwei@shu.edu.cn
}

Received 19 March 2014; Accepted 20 June 2014; Published 14 July 2014

Academic Editor: Haipeng Peng

Copyright (c) 2014 Wei Lv et al. This is an open access article distributed under the Creative Commons Attribution License, which permits unrestricted use, distribution, and reproduction in any medium, provided the original work is properly cited.

\begin{abstract}
This study is intended to provide a parameter identification method to determine salinity of sea ice by temperature and salinity observations. A quasilinear thermodynamic system of sea ice with unknown salinity is described and its property is proved. Then, a parameter identification model is established and the existence of its optimal solution is discussed. The salinity profile is calculated by the temperature and salinity data, which were measured at Nella Fjord around Zhongshan Station, Antarctica, during the polar night time by the 22nd Chinese Antarctic Research Expedition. Another simulation for temperature profiles during different measurement periods is operated. Results show that better simulations of the salinity and temperature distribution are possible with the estimated parameters than Eicken's (Eicken 1992) and THESCI's (Lv et al. 2009). This method will help people understand the salinity evolution of sea ice more thoroughly.
\end{abstract}

\section{Introduction}

Sea ice accounts (in areal extent) for nearly two-thirds of the earth's ice cover [1]. It is both an important actor and an indicator of climate change [2]. Its salinity is the main difference from water ice. The input of brine from sea ice is important in the ocean interaction, through modification of the density of the surface layer and the induction of thermohaline convection [3]. Salinity may also affect largescale sea ice and ocean characteristics [4]. Therefore, the physical properties of sea ice are thus strongly dependent on salinity.

Salinity has long fascinated sea ice researchers for the complexity that it produces through depression of freezing and melting temperatures [5]. Malmgren [6] discussed the evolution of the vertical salinity profile and recognized its effect on the thermal properties of sea ice. In evaluation of salinity data, most researchers resort to studying mean values integrated over the thickness of an entire floe. Most of this work has concentrated on the Arctic and Antarctic [7-10]. Eicken's ice-core based classification of ice salinity profiles features typical profiles that differ significantly from their
Arctic counterparts [8]. Although the seasons were not evenly sampled, Eicken's classification provides a general idea of the salinity profile in Antarctic sea ice.

The above researchers' methods to determine the ice salinity are according to salinity observations. The salinity measurement is by hand, and the field data are spare and unsatisfactory due to the difficulties associated with fieldwork, especially during the polar winter; thus it could not help people to thoroughly understand the physical evolution of sea ice salinity just by salinity data. Parameter identification method is effective in solving this problem. Identification refers to the determination from observed data of unknown parameters in the system model such that the predicted response of the model is close, in some well-defined sense, to the process observations [11]. In recent years, there are many researchers devoted to the identification problems. In [1214], parameter identification problems were performed via chaotic ant swarm. A semigroup approach to the mathematical analysis of the inverse coefficient problems of identifying the unknown coefficient in the quasilinear parabolic equation with Dirichlet boundary conditions was presented [15]. References $[16,17]$ provided the mathematical theory to calculate 
the ice densities, specific heats, and thermal conductivities. In [18], an ice salinity profile was determined by the parameter identification method abbreviated by THESCI.

In this paper, a parameter identification method to determine salinity using salinity and temperature observations is presented. Different to [18], a quasilinear thermodynamic system without a source term is chosen. The existence and uniqueness of the solution for the system are proved. The coefficients describing the salinity of sea ice are taken as the identified parameters, the deviation sum of the temperature and the salinity is defined as the performance criterion, and a parameter identification model is constructed; the existence of the identified parameters is presented. There are many powerful optimal algorithms to solve this problem, such as chaotic particle swarm optimization and chaotic ant swarm. To get the optimal solution, an optimization algorithm is constructed on the basis of Genetic Algorithm, HookeJeeves Algorithm, and semi-implicit difference scheme. The numerical results will be compared with Eicken's [8] and THESCI's [18]. The main contribution of this paper is that we not only provide a new method to determine the salinity of sea ice but also present its mathematical theory.

The objective of this study is to present a new method to determine the ice salinity and better understand the salinity profiles. Section 2 describes the quasilinear thermodynamic system of sea ice and its property. A parameter identification model is constructed and the existence for the optimal solution is proved in Section 3. Section 4 performs a numerical experiment and compares it to Eicken's [8] and THESCI's [18]. Final conclusions follow in Section 5.

\section{Quasilinear Thermodynamic System of Sea Ice}

For the purpose of describing the salinity profile more accurately, the thermodynamic system of sea ice not containing a source term at the polar night is presented. Since the gradient variation in the vertical direction is far greater than the one in the horizontal direction, we only consider the heat flux in the vertical direction. Let $z$ representing the depth of the system be the vertical coordinate taken as positive downward and let the origin be at some point on the ice surface, and the unit is in meters; the area we consider is from $l_{1}$ meter to $l_{2}$ meter depth, and $0<l_{1}<l_{2}$. Let $t$ denote time, $t_{f}(>0)$ the final time, and the unit is in seconds. Let $T(z, t)$ be the temperature at depth $z$ and time $t$, and the unit is in Kelvins. Let $\Omega=\left(l_{1}, l_{2}\right) \subset \mathbb{R}$, $I=\left(0, t_{f}\right), Q=\Omega \times I$. For convenience, set $\mathbb{\square}_{n}=\{1,2, \ldots, n\}$, and $n$ is any positive integer. According to Fourier's law of heat conduction, the thermodynamic system is described by the following heat conduction equations denoted by QTS:

$$
\begin{gathered}
C(z, t, T) \frac{\partial T}{\partial t}=\frac{\partial}{\partial z}\left(k(z, t, T) \frac{\partial T}{\partial z}\right), \quad \text { in } Q, \\
T(z, 0)=T_{0}(z), \quad \text { in } \bar{\Omega}, \\
T\left(l_{1}, t\right)=T_{U}(t), \quad \text { in } \bar{I}, \\
T\left(l_{2}, t\right)=T_{L}(t), \quad \text { in } \bar{I},
\end{gathered}
$$

where $k(z, t, T)$ is the thermal conductivity of sea ice and $C(z, t, T)$ is the heat capacity of sea ice, which are expressed by the following formulae on the basis of previous work [19]. For more applications, the ice salinity is taken as mean salinities determined for ice normalized-depth which is the ratio of the ice depth and the ice thickness. So the salinity is calculated by the following cubic polynomial function:

$$
\begin{gathered}
C(z, t, T)=\rho_{p i} c_{p i}+\frac{\gamma S(z, t)}{(T-273.15)^{2}}, \quad \text { in } Q, \\
k(z, t, T)=k_{p i}+\frac{\beta S(z, t)}{T-273.15}, \quad \text { in } Q, \\
S(z, t)=S(\widehat{z})=q_{1}+q_{2} \widehat{z}+q_{3} \widehat{z}^{2}+q_{4} \widehat{z}^{3}, \quad \text { in } Q, \\
\widehat{z}=\frac{z}{h(t)}, \quad \text { in } Q,
\end{gathered}
$$

where $\rho_{p i}, c_{p i}$, and $k_{p i}$ denote the density, specific heat, and thermal conductivity of pure ice, respectively; $\gamma$ and $\beta$ are known positive constants; $\widehat{z}$ is the normalized- depth; $h(t)$ is the ice thickness; $S(z, t)$ is the mean salinity of sea ice; and $q_{1}$, $q_{2}, q_{3}$, and $q_{4}$ are the unknown parameters describing the ice salinity, which will be estimated.

Assumption 1. There exist $q_{L i}>0, q_{U i}>0$, and $q_{L i} \leq q_{U i}$, for any $(z, t) \in \bar{Q}$, such that $q_{L i} \leq q_{i} \leq q_{U i}, i \in \mathbb{\nabla}_{4}$.

Assumption 2. Consider $T_{L}(t) \in C^{1}\left(\bar{I} ; \mathbb{R}^{+}\right), T_{U}(t) \quad \in$ $C^{1}\left(\bar{I} ; \mathbb{R}^{+}\right), T_{0}(z) \in C^{1}\left(\bar{\Omega} ; \mathbb{R}^{+}\right), h(t) \in C^{1}\left(\bar{I} ; \mathbb{R}^{+}\right)$.

Remark 3. From Assumptions 1 and 2, we can get $S(z, t) \in$ $C^{1}\left(\bar{Q} ; \mathbb{R}^{+}\right)$. And for any $(z, t) \in \bar{Q}$, there exist $h_{M}>0, S_{M Z}>$ $0, S_{M T}>0, S_{L}>0, S_{U}>0, S_{L} \leq S_{U}$, such that $|h| \leq h_{M}$, $\left|S_{t}\right| \leq S_{M T},\left|S_{z}\right| \leq S_{M Z}$, and $S_{L} \leq S(z, t) \leq S_{U}$.

From Remark 3, we make the following assumption.

Assumption 4. Consider $\beta S_{U}<273.15 k_{p i}$.

Remark 5. From the expression of $C(z, t, T)$, we get that $C(z, t, T)>0$, which squares with the facts of science.

Remark 6. Because $k(z, t, T)$ is the thermal conductivity of sea ice, we can get that $k(z, t, T)>0$. In fact, if $k(z, t, T)=0$, there is no heat transmitted through sea ice; if $k(z, t, T)<0$, which shows that heat is transmitted from low temperature to high temperature. Therefore $k(z, t, T) \leq 0$ is not in accordance with the laws of science.

From Remarks 5 and 6, we make the following assumption.

Assumption 7. Take $\Psi(z, 0)=T_{0}(z), \Psi\left(l_{1}, t\right)=T_{U}(t)$, $\Psi\left(l_{2}, t\right)=T_{L}(t), \Psi(z, t) \in H^{2+\alpha, 1+\alpha / 2}(\bar{Q})$, and satisfy

$$
\begin{aligned}
& {\left[\Psi_{t}(z, 0)-a_{11}\left(z, 0, \Psi(z, 0), \Psi_{z}(z, 0)\right)\right.} \\
& \left.\quad \times \Psi_{z z}(z, 0)+a\left(z, 0, \Psi(z, 0), \Psi_{z}(z, 0)\right)\right]\left.\right|_{z=l_{1}, l_{2}}=0,
\end{aligned}
$$


where

$$
\begin{aligned}
& a_{11}\left(z, 0, \Psi(z, 0), \Psi_{z}(z, 0)\right)=\frac{k(T)}{C(T)}, \\
& a\left(z, 0, \Psi(z, 0), \Psi_{z}(z, 0)\right)=-\frac{k_{z} T_{z}}{C(T)} .
\end{aligned}
$$

Remark 8. From Assumption 1 and Remark 3, we define

$$
\begin{gathered}
Q_{a d}=\left\{q=\left(q_{1}, q_{2}, q_{3}, q_{4}\right) \mid 0<q_{L j} \leq q_{j} \leq q_{U j},\right. \\
\left.j \in \mathbb{U}_{4}, S_{L} \leq \sum_{i=1}^{4} q_{i} \bar{z}^{i-1} \leq S_{U}\right\} ;
\end{gathered}
$$

then $Q_{a d}$ is a compact convex subset of $\mathbb{R}^{4}$.

From the above analysis, we can get the following results.

Theorem 9. Suppose Assumptions 1-7 hold; then there exists a unique solution $T(z, t) \in H^{2+\alpha, 1+\alpha / 2}(\bar{Q})$ satisfying QTS.

Proof. Take $\partial T / \partial t=T_{t}, \partial T / \partial z=T_{z}, \partial^{2} T / \partial z^{2}=T_{z z}$, $\Psi(z, 0)=T_{0}(z), \Psi\left(l_{1}, t\right)=T_{U}(t), \Psi\left(l_{2}, t\right)=T_{L}(t)$; then QTS can be written as

$$
\begin{aligned}
T_{t}-\frac{k(z, t, T)}{C(z, t, T)} T_{z z} & -\frac{k_{z}(z, t, T)}{C(z, t, T)} T_{z}=0, \quad \text { in } Q, \\
\Psi(z, 0) & =T_{0}(z), \quad \text { in } \bar{\Omega}, \\
\Psi\left(l_{1}, t\right) & =T_{U}(t), \quad \text { in } \bar{I}, \\
\Psi\left(l_{2}, t\right) & =T_{L}(t), \quad \text { in } \bar{I},
\end{aligned}
$$

where

$$
\begin{gathered}
\frac{k(z, t, T)}{C(z, t, T)}=\frac{k_{p i}(T-273.15)^{2}+\beta S(T-273.15)}{\rho_{p i} c_{p i}(T-273.15)^{2}+\gamma S}, \quad \text { in } Q, \\
\frac{k_{z}(z, t, T)}{C(z, t, T)}=\frac{\beta\left(S_{z}(T-273.15)-S T_{z}\right)}{\rho_{p i} c_{p i}(T-273.15)^{2}+\gamma S}, \quad \text { in } Q, \\
S_{z}(z, t)=\frac{q_{2}}{h(t)}+\frac{2 q_{3} z}{h^{2}(t)}+\frac{3 q_{4} z^{2}}{h^{3}(t)}, \quad \text { in } Q .
\end{gathered}
$$

Let

$$
\begin{aligned}
a_{11}\left(z, t, T, T_{z}\right) & =\frac{k(z, t, T)}{C(z, t, T)} \\
& =\frac{k_{p i}(T-273.15)^{2}+\beta S(T-273.15)}{\rho_{p i} c_{p i}(T-273.15)^{2}+\gamma S}, \\
a\left(z, t, T, T_{z}\right) & =-\frac{k_{z}(z, t, T) T_{z}}{C(z, t, T)} \\
& =-\frac{\beta T_{z}\left(S_{z}(T-273.15)-S T_{z}\right)}{\rho_{p i} c_{p i}(T-273.15)^{2}+\gamma S} .
\end{aligned}
$$

The expression of $a_{11}\left(z, t, T, T_{z}\right)$ is none of $T_{z}$, so $a_{11}\left(z, t, T, T_{z}\right)$ is written as $a_{11}(z, t, T)$. Then (6) can be written as

$$
T_{t}-a_{11}(z, t, T) T_{z z}+a\left(z, t, T, T_{z}\right)=0, \quad \text { in } Q .
$$

From Remarks 5 and 6, for $\forall(z, t) \in \bar{Q}, \forall T$, we have

$$
a_{11}(z, t, T)=\frac{k(T)}{C(T)}>0
$$

From the expression of $a\left(z, t, T, T_{z}\right)$, for $\forall b_{1} \geq 0$, we have

$$
T a(z, t, T, 0)=0 \geq-b_{1} T^{2} .
$$

For $\forall(z, t) \in \bar{Q}, \forall|T| \leq M=273.15-\beta S / k_{p i}, \forall p \triangleq T_{z}$, we can get that $a_{11}(z, t, T)$ and $a(z, t, T, p)$ are continuous. And

$$
\frac{\partial a_{11}(z, t, T)}{\partial p}=0,
$$

$$
\begin{aligned}
& \frac{\partial a_{11}(z, t, T)}{\partial T} \\
& =-\frac{\beta S \rho_{p i} c_{p i}(T-273.15)^{2}-2 k_{p i} S \gamma(T-273.15)-\beta \gamma S^{2}}{\left[\rho_{p i} c_{p i}(T-273.15)^{2}+\gamma S\right]^{2}},
\end{aligned}
$$

$$
\begin{aligned}
& \frac{\partial a_{11}(z, t, T)}{\partial z} \\
& =\frac{(T-273.15)^{2} S_{z}\left[\beta \rho_{p i} c_{p i}(T-273.15)-\gamma k_{p i}\right]}{\left[\rho_{p i} c_{p i}(T-273.15)^{2}+\gamma S\right]^{2}} .
\end{aligned}
$$

It is obvious that $\partial a_{11} / \partial p, \partial a_{11} / \partial T$, and $\partial a_{11} / \partial z$ are continuous, so $a_{11}(z, t, T)$ is differential with respect to $z, T$, and $p$ for $\forall(z, t) \in \bar{Q}, \forall|T| \leq M, \forall p$.

Take

$$
\begin{gathered}
\nu=\frac{k_{p i}(M-273.15)^{2}+\beta S_{L}|M-273.15|}{\rho_{p i} c_{p i}(M+273.15)^{2}+\gamma S_{U}}>0, \\
\mu=\frac{k_{p i}(M+273.15)^{2}+\beta S_{U}(M+273.15)}{\rho_{p i} c_{p i}(M-273.15)^{2}+\gamma S_{L}}>0 ;
\end{gathered}
$$

then for $\forall(z, t) \in \bar{Q}, \forall|T| \leq M, \forall p$, we have that $v \leq$ $a_{11}(z, t, T(z, t)) \leq \mu$. 
For $\forall(z, t) \in \bar{Q}, \forall|T| \leq M, \forall p$, we have

$$
\begin{aligned}
& \frac{\left|\partial a_{11} / \partial z\right|}{1+|p|} \\
& =\frac{\left|\rho_{p i} c_{p i} k_{p i}(T-273.15)^{4}-\rho_{p i} c_{p i} \beta\left(S_{z}-S\right)(T-273.15)^{3}\right|}{(1+|p|)\left[\rho_{p i} c_{p i}(T-273.15)^{2}+\gamma S\right]^{2}} \\
& +\frac{\gamma k_{p i} S_{z}(T-273.15)^{2}}{(1+|p|)\left[\rho_{p i} c_{p i}(T-273.15)^{2}+\gamma S\right]^{2}} \\
& \leq \frac{\rho_{p i} c_{p i} k_{p i}(M+273.15)^{4}+\rho_{p i} c_{p i} \beta\left(S_{M Z}+S_{U}\right)(M+273.15)^{3}}{\left[\rho_{p i} c_{p i}(M-273.15)^{2}+\gamma S_{L}\right]^{2}} \\
& \triangleq M_{1} \text {, } \\
& \left|\frac{\partial a_{11}}{\partial T}\right| \\
& =\frac{\left|\beta S \rho_{p i} c_{p i}(T-273.15)^{2}-2 k_{p i} S \gamma(T-273.15)-\beta \gamma S^{2}\right|}{\left[\rho_{p i} c_{p i}(T-273.15)^{2}+\gamma S\right]^{2}} \\
& \leq \frac{\beta S_{U} \rho_{p i} c_{p i}(M+273.15)^{2}+2 k_{p i} S_{U} \gamma(M+273.15)+\beta \gamma S_{U}^{2}}{\left[\rho_{p i} c_{p i}(M-273.15)^{2}+\gamma S_{L}\right]^{2}} \\
& \triangleq M_{2} \text {, } \\
& \frac{|a|}{(1+|p|)^{2}} \\
& =\frac{\left|\beta S p^{2}-\beta S_{z}(T-273.15) p\right|}{(1+|p|)^{2}\left[\rho_{p i} c_{p i}(T-273.15)^{2}+\gamma S\right]} \\
& \leq \frac{\beta \max \left\{S_{U}, S_{M Z}(M+273.15)\right\}}{\rho_{p i} c_{p i}(M-273.15)^{2}+\gamma S_{L}} \triangleq M_{3} \text {. }
\end{aligned}
$$

So

$$
\begin{aligned}
& \left|\frac{\partial a_{11}}{\partial p}\right|(1+|p|)^{3}+\left|\frac{\partial a_{11}}{\partial T}\right|(1+|p|)^{2} \\
& +\left|\frac{\partial a_{11}}{\partial z}\right|(1+|p|)+|a(z, t, T, p)| \\
& \quad=\left(\frac{\left|\partial a_{11} / \partial z\right|}{1+|p|}+\left|\frac{\partial a_{11}}{\partial T}\right|+\frac{|a(z, t, T, p)|}{(1+|p|)^{2}}\right)(1+|p|)^{2} \\
& \quad \leq\left(M_{1}+M_{2}+M_{3}\right)(1+|p|)^{2} .
\end{aligned}
$$

For any $(z, t) \in \bar{Q}$, we can get

$$
\begin{aligned}
\left|\frac{\partial a_{11}}{\partial t}\right| & =\left|\frac{S_{t}(T-273.15)^{2}\left[\beta \rho_{p i} c_{p i}(T-273.15)-\gamma k_{p i}\right]}{\left[\rho_{p i} c_{p i}(T-273.15)^{2}+\gamma S\right]^{2}}\right| \\
& \leq \frac{S_{M T}(M+273.15)^{2}\left[\beta \rho_{p i} c_{p i}(M+273.15)+\gamma k_{p i}\right]}{\left[\rho_{p i} c_{p i}(M-273.15)^{2}+\gamma S_{L}\right]^{2}} .
\end{aligned}
$$

So $\partial a_{11} / \partial t$ is bound. And $\partial a_{11} / \partial z$ and $\partial a_{11} / \partial T$ are also bound; we can get that $a_{11}(z, t, T)$ is Lipschitz continuous on $z, t, T$.

For $\forall(z, t),\left(z^{\prime}, t^{\prime}\right) \in \bar{Q} ; \forall T, T^{\prime},|T| \leq M,\left|T^{\prime}\right| \leq M$; $\forall p, p^{\prime}$, and $|p| \leq M_{p},\left|p^{\prime}\right| \leq M_{p}$, set $\Lambda=\left(l_{1}, l_{2}\right) \times\left(0, t_{f}\right) \times$ $(-M, M)$, and we have that

$$
\begin{aligned}
& \left\|a_{11}(z, t, T)\right\|_{H^{\alpha, \alpha / 2}(\bar{\Lambda})} \sup _{(z, t, T),\left(z^{\prime}, t, T\right) \in \bar{\Lambda},\left|z-z^{\prime}\right| \leq 2 l_{2}-2 l_{1}} \frac{\left|a_{11}(z, t, T)-a_{11}\left(z^{\prime}, t, T\right)\right|}{\left|z-z^{\prime}\right|^{\alpha}} \\
& \quad+\sup _{(z, t, T),\left(z, t^{\prime}, T\right) \in \bar{\Lambda},\left|t-t^{\prime}\right| \leq 2 t_{f}} \frac{\left|a_{11}(z, t, T)-a_{11}\left(z, t^{\prime}, T\right)\right|}{\left|t-t^{\prime}\right|^{\alpha / 2}} \\
& \quad+\sup _{(z, t, T),\left(z, t, T^{\prime}\right) \in \bar{\Lambda},\left|T-T^{\prime}\right| \leq 2 M} \frac{\left|a_{11}(z, t, T)-a_{11}\left(z, t, T^{\prime}\right)\right|}{\left|T-T^{\prime}\right|^{\alpha}} \\
& \quad+\max _{\bar{\Lambda}}\left|a_{11}(z, t, T)\right| \\
& =\sup _{(z, t, T),\left(z^{\prime}, t, T\right) \in \bar{\Lambda},\left|z-z^{\prime}\right| \leq 2 l_{2}-2 l_{1}} \frac{\left|a_{11}(z, t, T)-a_{11}\left(z^{\prime}, t, T\right)\right|}{\left|z-z^{\prime}\right|} \\
& \quad \cdot\left|z-z^{\prime}\right|^{1-\alpha} \\
& \quad+\sup _{(z, t, T),\left(z, t^{\prime}, T\right) \in \bar{\Lambda},\left|t-t^{\prime}\right| \leq 2 t_{f}} \frac{\left|a_{11}(z, t, T)-a_{11}\left(z, t^{\prime}, T\right)\right|}{\left|t-t^{\prime}\right|} \\
& \quad \cdot\left|t-t^{\prime}\right|^{1-\alpha / 2} \\
& +\operatorname{sip}_{(z, t, T),\left(z, t, T^{\prime}\right) \in \bar{\Lambda},\left|T-T^{\prime}\right| \leq 2 M} \frac{\left|a_{11}(z, t, T)-a_{11}\left(z, t, T^{\prime}\right)\right|}{\left|T-T^{\prime}\right|} \\
& \quad \cdot\left|T-T^{\prime}\right|^{1-\alpha}+\max _{\bar{\Lambda}}\left|a_{11}(z, t, T)\right| \\
& <\infty .
\end{aligned}
$$

Therefore, $a_{11}(z, t, T)$ is Hölder continuous in the variable $t$ with the exponent $\alpha / 2$ and in $z, T$, and $p$ with $\alpha$.

Obviously, we can also get that $a(z, t, T, p)$ is Hölder continuous in the variable $t$ with the exponent $\alpha / 2$ and in the variables $z, T$, and $p$ with the exponent $\alpha$.

From the above analysis, Assumption 7 and Theorem 5.2 [20], we can get that there exists a unique solution $T(z, t) \in H^{2+\alpha, 1+\alpha / 2}(\bar{Q})$ satisfying QTS, which completes our proof.

\section{Parameter Identification Model}

For the purpose of making the salinity and temperature of sea ice be close to the actual process observations, a parameter identification model is established as PIM:

$$
\begin{aligned}
\min J(q)= & \left\|\frac{T(z, t ; q)-T_{\text {mea }}(z, t)}{T_{\max }}\right\|_{L^{2}(Q)}^{2} \\
& +\left\|\frac{S(\widehat{z} ; q)-S_{\text {mea }}(\widehat{z})}{S_{\max }}\right\|_{L^{2}[0,1]}^{2}
\end{aligned}
$$




$$
\begin{aligned}
\text { s.t. } \quad T(z, t ; q) & \in H^{2+\alpha, 1+\alpha / 2}(\bar{Q}) \\
q & \in Q_{a d},
\end{aligned}
$$

where $T_{\text {mea }}(z, t)$ and $S_{\text {mea }}(z, t)$ are the field data of the temperature and salinity and $T_{\max }$ and $S_{\max }$ denote the maximums among the field data. Here the temperature unit is taken as Kelvin, and the salinity's ppt. Since units are different, the temperature and salinity in $J(q)$ are normalized. Our goal is to estimate the salinity coefficients such that the temperature and salinity values computed from QTS most closely reproduce these observations.

3.1. Existence of Optimal Parameter. The next theorem presents the existence of the identified parameters for the identification model.

Theorem 10. Suppose Assumptions 1-7 hold; then there exists one optimal solution $q^{*} \in Q_{a d}$ satisfying PIM.

Proof. For any parameter $q \in Q_{a d}$, let $\left\{q_{n}\right\} \subset Q_{a d}$ be a sequence, such that $\left\|q_{n}-q\right\|_{Q_{a d}} \rightarrow 0$ as $n \rightarrow \infty$. Let $T_{n}=$ $T\left(q_{n}\right)$ and $T=T(q)$ be the solutions of QTS. Then we have that

$$
\begin{aligned}
& \left\|T_{n}-T\right\|_{H^{2+\alpha, 1+\alpha / 2}(\bar{Q})} \\
& =\sup _{(z, t),\left(z^{\prime}, t\right) \in \overline{\mathrm{Q}},\left|z-z^{\prime}\right| \leq 2 l_{2}-2 l_{1}} \mid D_{z}^{2}\left(T_{n}-T\right)(z, t) \\
& -D_{z}^{2}\left(T_{n}-T\right)\left(z^{\prime}, t\right) \\
& \times\left(\left|z-z^{\prime}\right|^{\alpha}\right)^{-1} \\
& +\sup _{(z, t, T),\left(z, t^{\prime}, T\right) \in \overline{\mathrm{Q}},\left|z-z^{\prime}\right| \leq 2 l_{2}-2 l_{1}} \mid D_{t}\left(T_{n}-T\right)(z, t) \\
& -D_{t}\left(T_{n}-T\right)\left(z^{\prime}, t\right) \\
& \times\left(\left|z-z^{\prime}\right|^{\alpha}\right)^{-1} \\
& +\sup _{(z, t, T),\left(z, t^{\prime}, T\right) \in \overline{\mathrm{Q}},\left|t-t^{\prime}\right| \leq 2 t_{f}} \mid D_{z}\left(T_{n}-T\right)(z, t) \\
& -D_{z}\left(T_{n}-T\right)\left(z, t^{\prime}\right) \\
& \times\left(\left|t-t^{\prime}\right|^{(1+\alpha) / 2}\right)^{-1} \\
& +\sup _{(z, t, T),\left(z, t^{\prime}, T\right) \in \bar{Q},\left|t-t^{\prime}\right| \leq 2 t_{f}} \mid D_{t}\left(T_{n}-T\right)(z, t) \\
& -D_{t}\left(T_{n}-T\right)\left(z, t^{\prime}\right) \\
& \times\left(\left|t-t^{\prime}\right|^{\alpha / 2}\right)^{-1}
\end{aligned}
$$

$$
\begin{aligned}
& +\sup _{(z, t, T),\left(z, t^{\prime}, T\right) \in \bar{Q},\left|t-t^{\prime}\right| \leq 2 t_{f}} \mid D_{z}^{2}\left(T_{n}-T\right)(z, t) \\
& -D_{z}^{2}\left(T_{n}-T\right)\left(z, t^{\prime}\right) \mid \\
& \times\left(\left|t-t^{\prime}\right|^{\alpha / 2}\right)^{-1} \\
& +\max _{\bar{Q}}\left|T_{n}(z, t)-T(z, t)\right|+\max _{\bar{Q}}\left|D_{z}\left(T_{n}-T\right)(z, t)\right| \\
& +\max _{\bar{Q}}\left|D_{z}^{2}\left(T_{n}-T\right)(z, t)\right| \\
& +\max _{\bar{Q}}\left|D_{t}\left(T_{n}-T\right)(z, t)\right| \longrightarrow 0 \quad(n \longrightarrow \infty) .
\end{aligned}
$$

So we can get that the mapping $q \rightarrow T(q)$ is strongly continuous in $H^{2+\alpha, 1+\alpha / 2}(\bar{Q})$.

Next we get the existence of optimal solution.

For any $q \in Q_{a d}$, set $X_{1}(T ; q)=T(z, t ; q)-T_{\text {mea }}(z, t)$, $X_{2}(\widehat{z} ; q)=S(\widehat{z} ; q)-S_{\text {mea }}(\widehat{z})$; then

$$
J(q)=\left\|\frac{X_{1}(T ; q)}{T_{\text {mea }}(z, t)}\right\|_{L^{2}(\bar{Q})}^{2}+\left\|\frac{X_{2}(\widehat{z} ; q)}{S_{\text {mea }}(z, t)}\right\|_{L^{2}[0,1]}^{2} \geq 0 .
$$

Obviously, $X_{1}(T ; q)$ and $X_{2}(\widehat{z} ; q)$ are continuous on $Q_{a d}$; thus $J(q)$ is continuous on $Q_{a d}$. Since $Q_{a d}$ is a nonempty compact convex set, and the mapping $q \rightarrow T(q)$ is strongly continuous in $H^{2+\alpha, 1+\alpha / 2}(\bar{Q})$, there exists $q^{*} \in Q_{a d}$, for all $q \in Q_{a d}$, such that $J\left(q^{*}\right) \leq J(q)$; that is $q^{*} \in Q_{a d}$ is the optimal solution of PI.

Next section will give the algorithm to solve the identified model.

3.2. Algorithm. In this section, an algorithm is constructed to solve the above identification model.

To solve the model described in Section 2, the ice temperature $T$ in formula $J(q)$ should be calculated. So the first thing is to calculate the thermodynamic system QTS. Here we choose the semi-implicit finite difference scheme abbreviated to SIFDS, which is an approach with unconditional convergence. To get the optimal solution of the identified model, the Genetic Algorithm is used in conjunction with HookeJeeves Algorithm, where Genetic Algorithm and HookeJeeves Algorithm are abbreviated to GA and HJA, respectively. GA is a global search one, which can find the global minimum point in theory. HJA is a local search one. The combination of GA's good global search and HJA's accurate local search is a good manner to solve the model rapidly and effectively. The convergence is obvious. We will present the four-dimensional closed domain $P S$ for the identified vector $q$ and not give some value. The initial value for $q$ will be generated randomly in the domain. The stop criterion is a minor error $\varepsilon$ for $J(q)$ or a large iterative time IT. If the value of $J(q)$ is less than $\varepsilon$ or the iterative time is greater than $I T$, the program will stop. Next are the algorithm steps. 


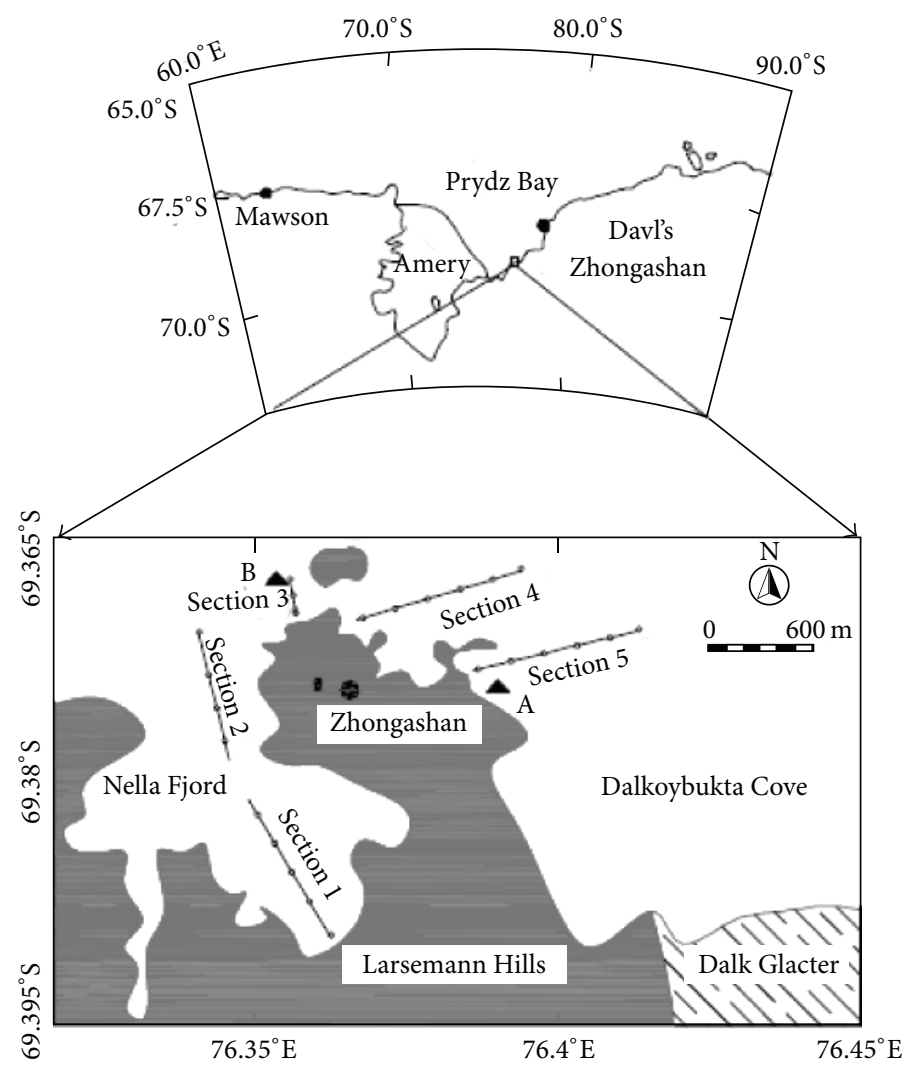

FIGURE 1: Locations of landfast ice survey areas in the vicinity of Zhongshan Station (solid circle) in 2006.

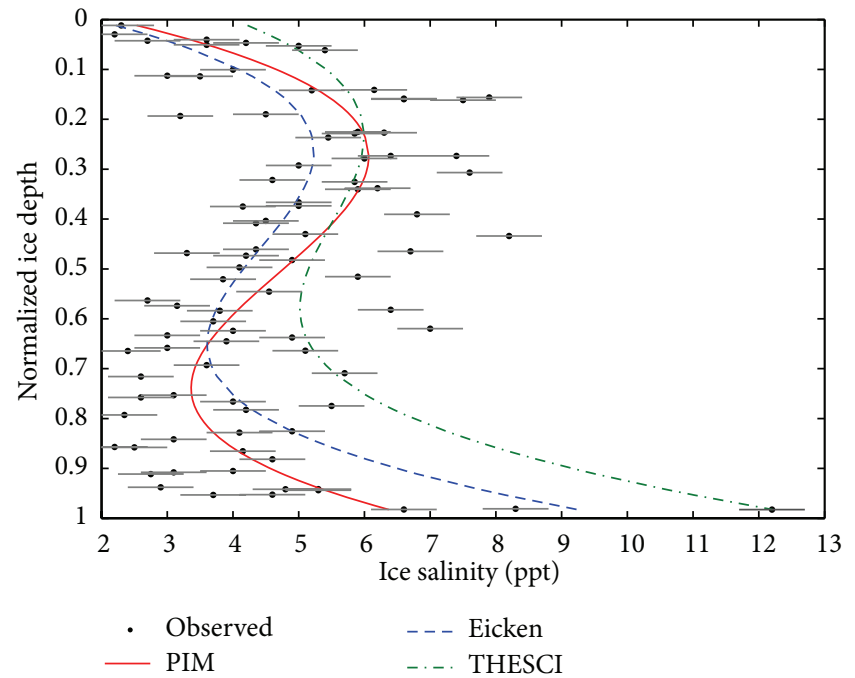

FIGURE 2: The mean salinity profile of sea ice.

Step 1. Give $P S, \varepsilon, I T$, and generate $q^{0} \in P S$ randomly; set $l=0$.

Step 2. Solve QTS for $T\left(q^{l}\right)$ by SIFDS, and calculate $J\left(q^{l}\right)$ by GA and HJA.
TABLE 1: List of model parameters and constants.

\begin{tabular}{lccc}
\hline Parameters & Symbols & Value & Unit \\
\hline $\begin{array}{l}\text { Density of pure ice } \\
\text { Specific heat of pure }\end{array}$ & $\rho_{\mathrm{pi}}$ & 916 & $\mathrm{Kg} \mathrm{m}^{-3}$ \\
$\begin{array}{l}\text { ice } \\
\text { Thermal conductivity } \\
\text { of pure ice }\end{array}$ & $k_{\mathrm{pi}}$ & 2093 & $\mathrm{~J} \mathrm{~kg}^{-1} \mathrm{~K}^{-1}$ \\
- & $\gamma$ & $1.715 \times 10^{7}$ & $\mathrm{JKm}^{-3} \mathrm{ppt}^{-1}$ \\
- & $\beta$ & 0.1172 & $\mathrm{~W} \mathrm{~m}^{-1} \mathrm{ppt}^{-1}$ \\
$\begin{array}{l}\text { Observed minimum } \\
\text { salinity }\end{array}$ & $S_{L}$ & 2.2 & $\mathrm{ppt}$ \\
$\begin{array}{l}\text { Observed maximum } \\
\text { salinity }\end{array}$ & $S_{U}$ & 13 & $\mathrm{ppt}$ \\
\hline
\end{tabular}

Step 3. If $J\left(q^{l}\right) \leq \varepsilon$ or $l \geq I T$, set $q^{*}=q^{l}$, and output $q^{*}$; else, go to Step 2 with $l=l+1$.

\section{An Experiment}

In this section, an experiment to estimate the parameters describing the ice salinity is performed. The field data are described in Section 4.1. Numerical results and discussions are performed in Section 4.2. 

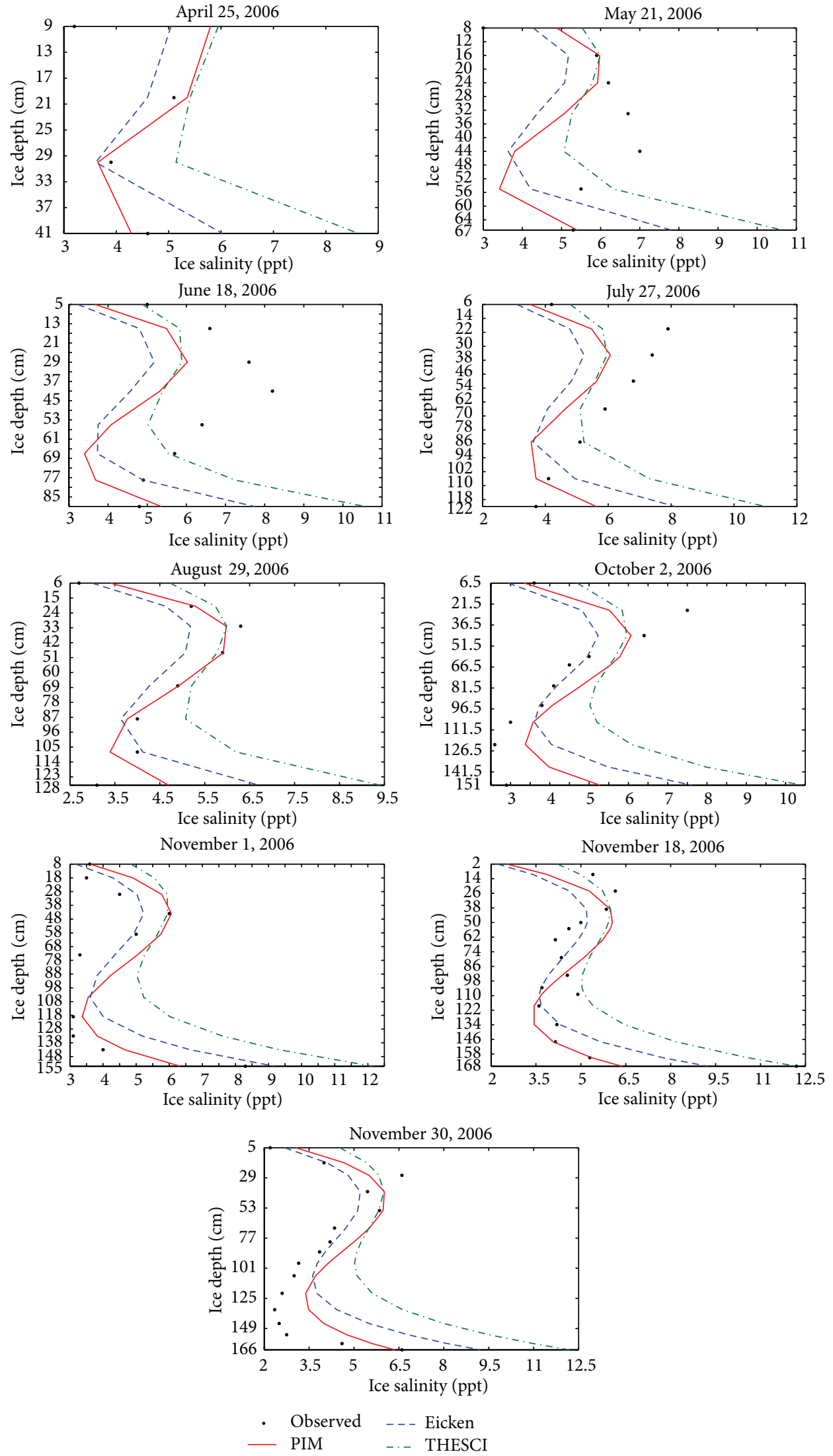

FIgure 3: The ice salinity profiles on April 25, May 21, June 18, July 27, August 29, October 2, November 1, November 18, and November 30. 

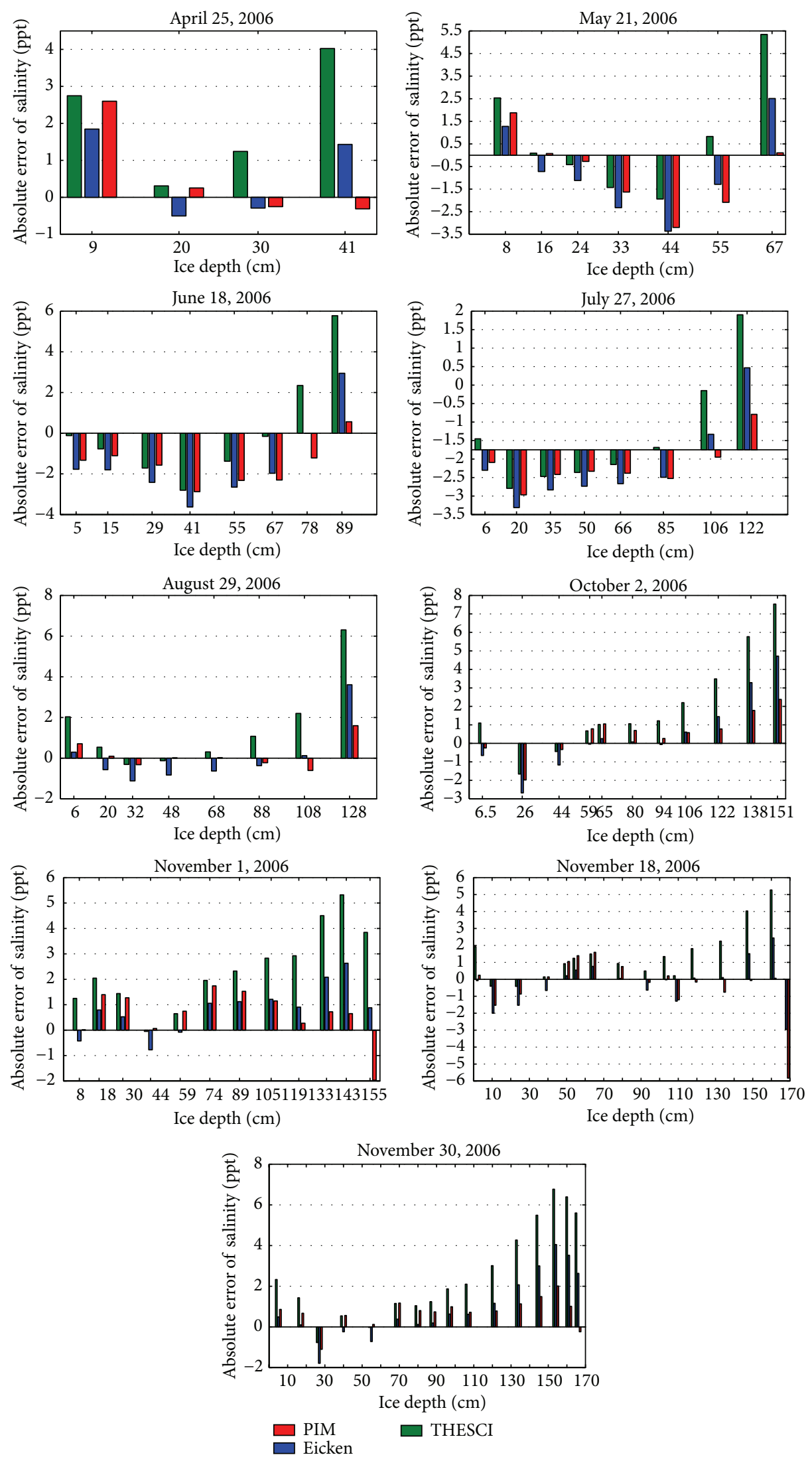

Figure 4: The absolute salinity profiles on April 25, May 21, June 18, July 27, August 29, October 2, November 1, November 18, and November 30. 

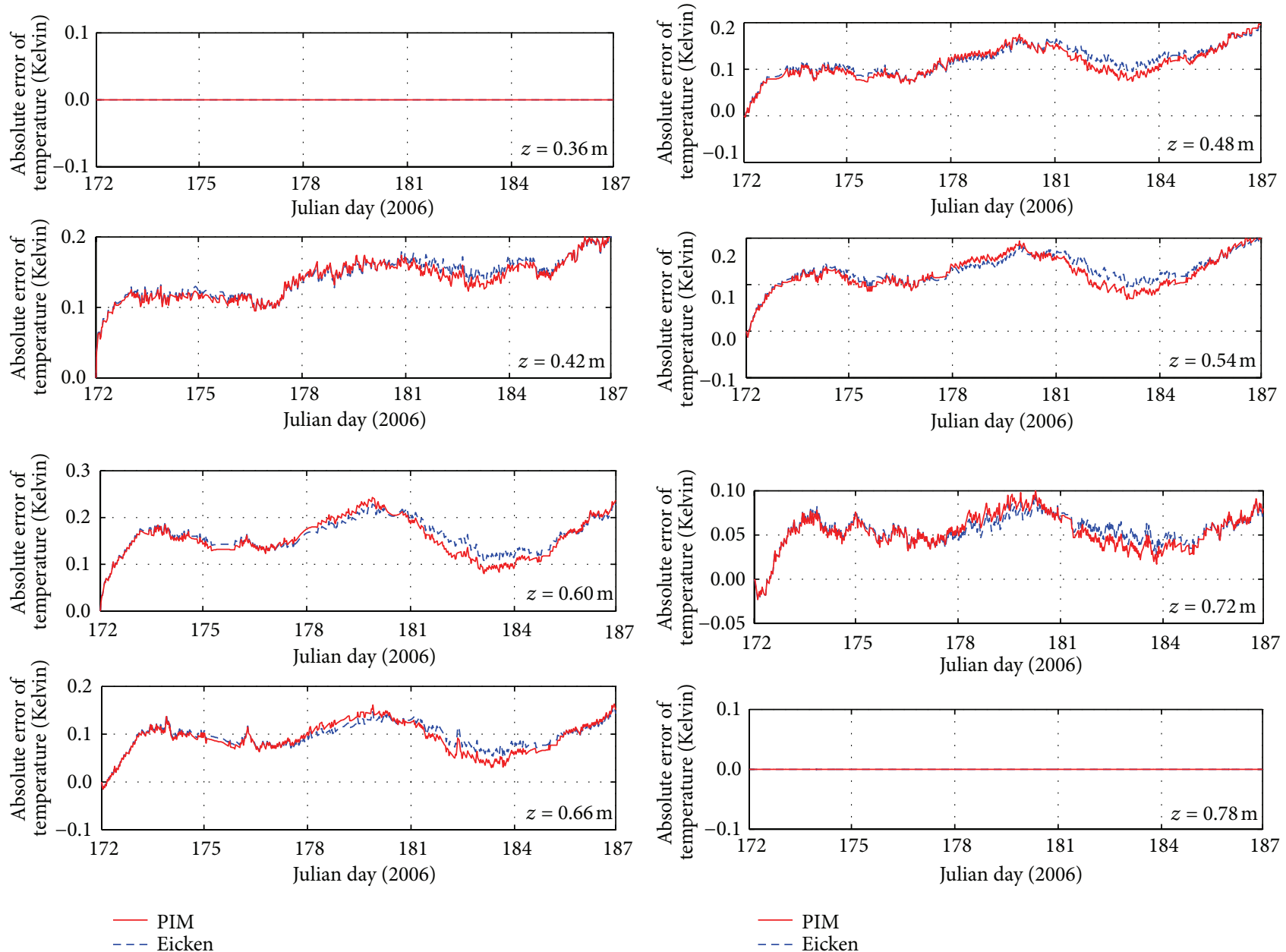

Figure 5: The absolute error configurations of the ice temperature at different depths from June 21 to July 5, 2006, for PIM and Eicken.

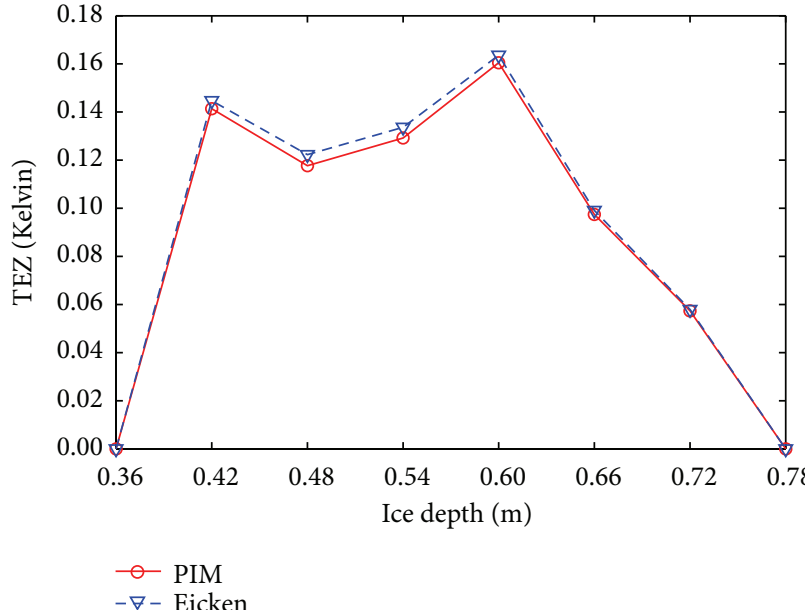

(a)

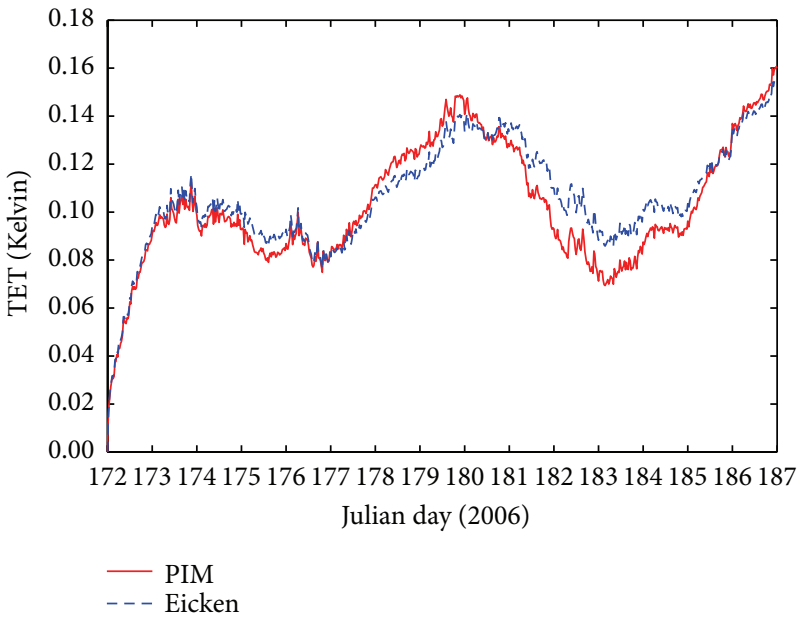

(b)

Figure 6: The temperature error configurations from June 21 to July 5, 2006, for PIM and Eicken. 

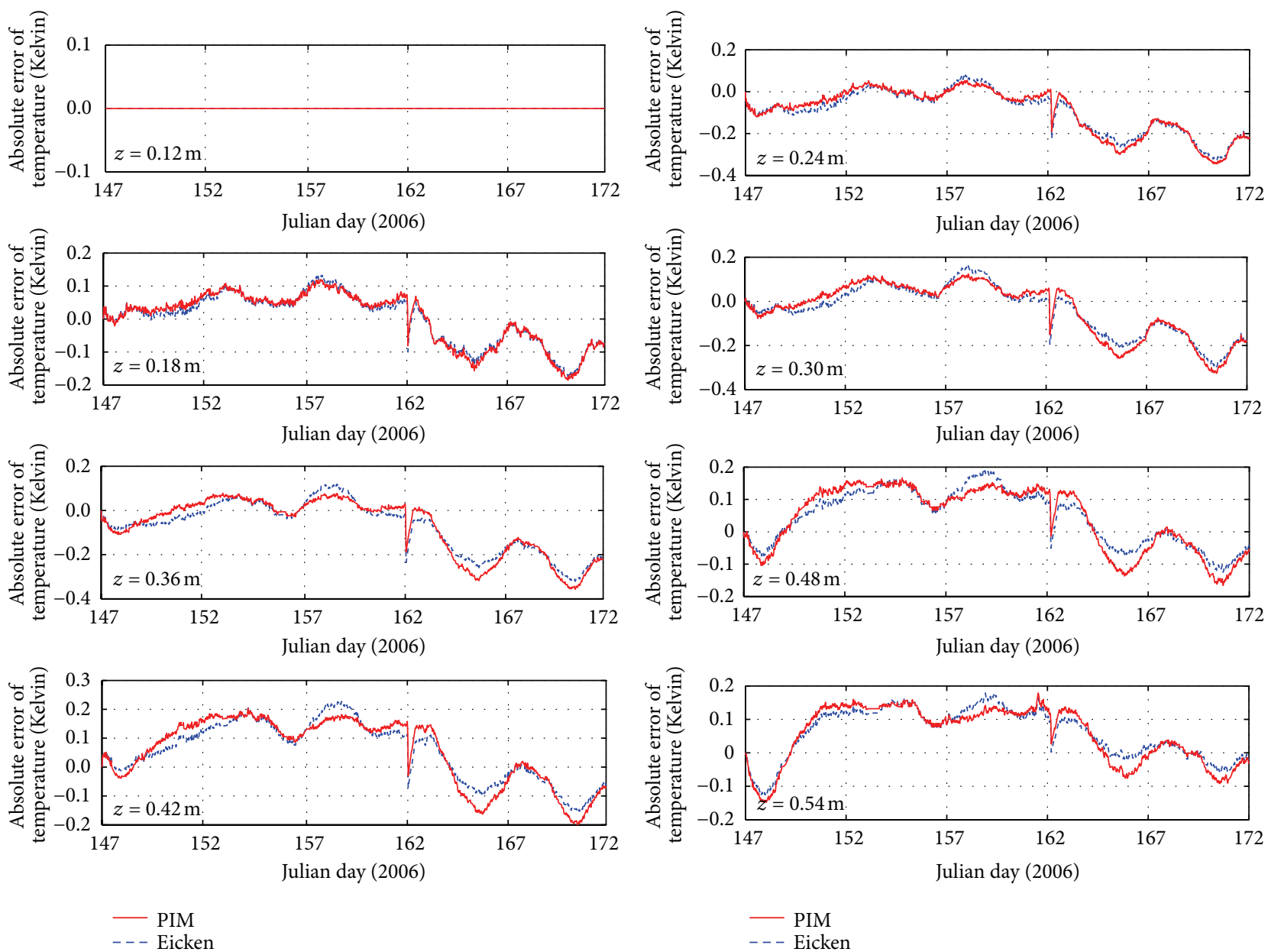

- - - Eicken
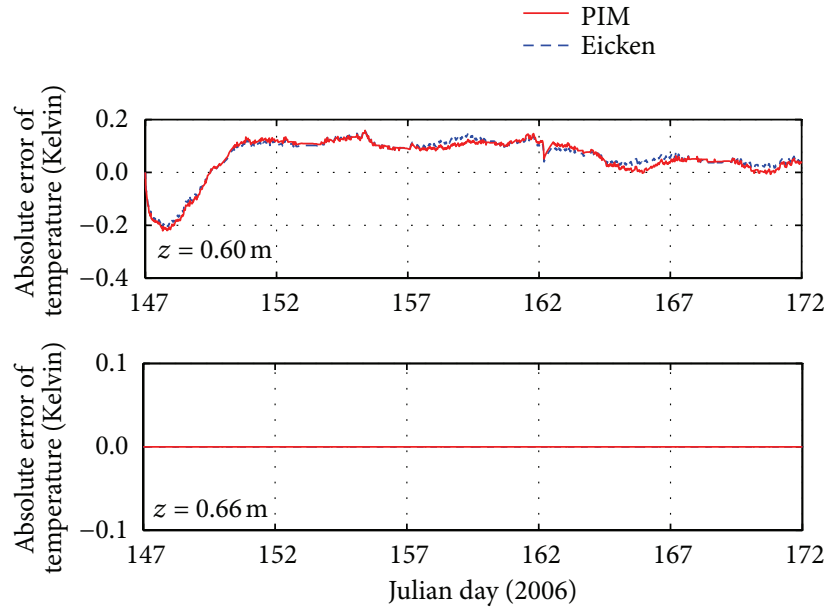

- PIM

FIGURE 7: The absolute error configurations of the ice temperature at different depths from May 27 to June 20, 2006, for PIM and Eicken.

The salinity and temperature errors are defined as

$$
\begin{gathered}
\operatorname{SE}(q)=\sqrt{\frac{1}{90}\left(\sum_{s=1}^{90}\left(S\left(\widehat{z}_{s} ; q\right)-S_{\text {mea }}\left(\widehat{z}_{s}\right)\right)^{2}\right)}, \\
\operatorname{TE} 1(q)=\sqrt{\frac{1}{\bar{i} \cdot \bar{j}} \sum_{j=1}^{\bar{j}} \sum_{i=1}^{\bar{i}}\left(T\left(z_{i}, t_{j} ; q\right)-T_{\text {mea }}\left(z_{i}, t_{j}\right)\right)^{2},}
\end{gathered}
$$

$$
\begin{array}{r}
\operatorname{TE} 2(q)=\frac{\sum_{j=1}^{\bar{j}} \sum_{i=1}^{\bar{i}}\left|T\left(z_{i}, t_{j} ; q\right)-T_{\text {mea }}\left(z_{i}, t_{j}\right)\right|}{\sum_{j=1}^{\bar{j}} \sum_{i=1}^{\bar{i}}\left|T_{\text {mea }}\left(z_{i}, t_{j}\right)\right|}, \\
\operatorname{TEZ}(z ; q)=\sqrt{\frac{1}{\bar{j}\left(\sum_{j=1}^{\bar{j}}\left(T\left(z_{i}, t_{j} ; q\right)-T_{\text {mea }}\left(z_{i}, t_{j}\right)\right)^{2}\right)},} \\
i=1, \ldots, \bar{i},
\end{array}
$$




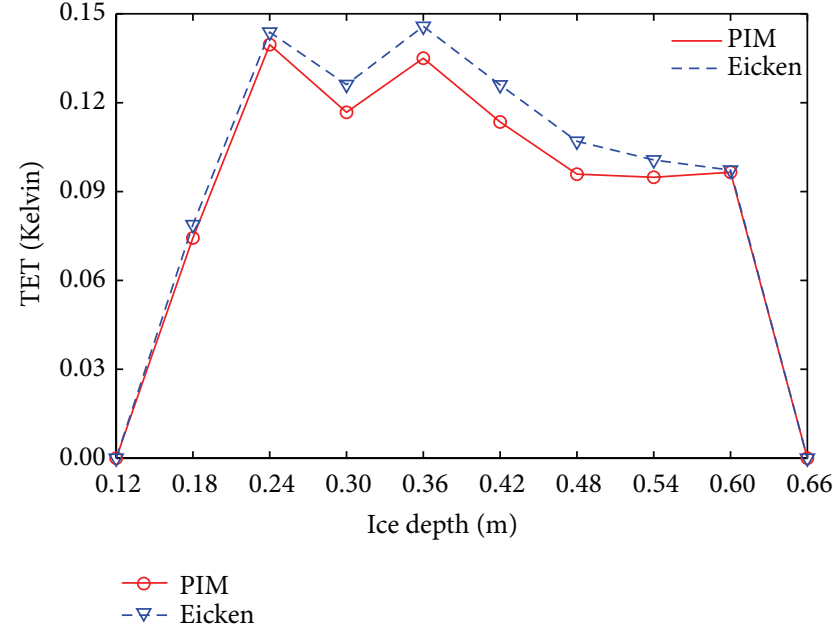

(a)

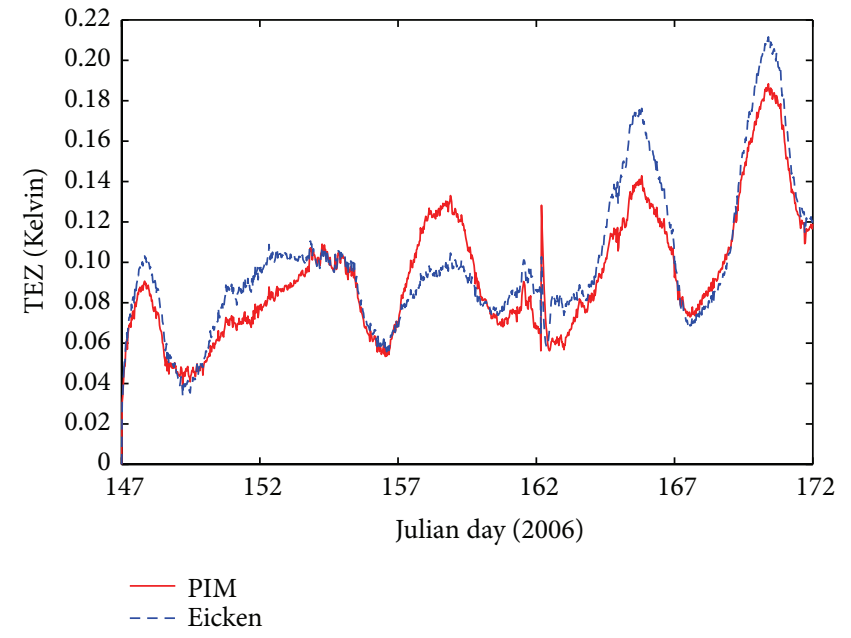

(b)

Figure 8: The temperature error configurations from May 27 to June 20, 2006, for PIM and Eicken.

TABLE 2: Salinity parameter values and salinity errors of three methods.

\begin{tabular}{lccccc}
\hline & $q_{1}$ & $q_{2}$ & $q_{3}$ & $q_{4}$ & SE \\
\hline PIM & 2.1667 & 32.5360 & -81.5137 & 53.6941 & 1.3671 \\
Eicken & 1.89 & 29.19 & -77.49 & 56.38 & 1.7808 \\
THESCI & 3.9998 & 19.6095 & -58.6298 & 48.0169 & 2.8175 \\
\hline
\end{tabular}

TABLE 3: Temperature errors for PIM and Eicken.

\begin{tabular}{lcccc}
\hline & TE1 & TE2 & TE1 & TE2 \\
& $(6 / 21-7 / 5)$ & $(6 / 21-7 / 5)$ & $(5 / 27-6 / 20)$ & $(5 / 27-6 / 20)$ \\
\hline PIM & 0.1055 & $0.0317 \%$ & 0.0986 & $0.0267 \%$ \\
Eicken & 0.1082 & $0.0329 \%$ & 0.1053 & $0.0284 \%$ \\
\hline
\end{tabular}

$$
\begin{array}{r}
\operatorname{TET}(t ; q)=\sqrt{\frac{1}{\bar{i}\left(\sum_{i=1}^{\bar{i}}\left(T\left(z_{i}, t_{j} ; q\right)-T_{\text {mea }}\left(z_{i}, t_{j}\right)\right)^{2}\right)},} \\
j=1, \ldots, \bar{j},
\end{array}
$$

where $\bar{i}$ and $\bar{j}$ are temperature numbers of measured spatial spots and temporal spots.

4.1. Field Data. The field data were measured by the 22nd Chinese Antarctic Research Expedition. The experimental site was located in the coastal area off Zhongshan Station (Figure 1). Figure 1 is seen in [21]. In the region, polar night occurs from late May to late July. Five survey sections were set up to monitor landfast ice (Figure 1). As shown in Figure 1, Section 3 was located north of the station, where the field data taken in this paper were measured.

Landfast ice off Zhongshan usually breaks off in early summer, often due to coincident high wind speeds, monthly peak tides, and/or the effect of penetrating ocean swell [21]. A thermistor string was deployed at northern end of Section 3 on 27 March at site B (Figure 1), where the water depth is $35 \mathrm{~m}$. At the time of installation, the ice thickness was $0.270 \mathrm{~m}$, with $0.015 \mathrm{~m}$ snow. The thermistor string was installed in an auger hole, which refroze naturally, and the portion of the hole above water level was filled with water of about 3 ppt. The temperature sensors in the first $1.26 \mathrm{~m}$ beneath the upper ice surface were spaced at $0.06 \mathrm{~m}$ intervals and at $0.12 \mathrm{~m}$ intervals below that. Each sensor extended by $0.02 \mathrm{~m}$ from the rod. The coherence of these sensors was controlled by selecting sensors whose reading was within $\pm 0.005 \mathrm{~K}$ of each other during calibration. From 31 March through 12 December 2006, ice temperatures were measured at $30 \mathrm{~min}$ interval and stored on board a DUT-5000 storage system. The data system was designed to hold 20-day data and the battery pack to provide powder for more than 20 days. The measured time for temperature data taken here is from May 27 to June 15, 2006 , which is the polar night time. To get more accurate results, we take $l_{1}=0.36 \mathrm{~m}$ and $l_{2}=0.66 \mathrm{~m}$. In the simulated temperature profiles, we take $l_{1}=0.12 \mathrm{~m}$ and $l_{2}=0.78 \mathrm{~m}$.

During 2006 ten full length ice cores were collected using a $0.13 \mathrm{~m}$ diameter corer within an area of $10 \mathrm{~m}$ by $10 \mathrm{~m}$ near the center of Section 3. The cores were cut lengthwise to obtain $0.05-0.15 \mathrm{~m}$ thick vertical sections. Sea ice salinity was measured using a portable conductivity meter DDBT-350 with an accuracy of $\pm 0.5 \mathrm{ppt}$ [21]. Here we take the salinity data of 9 ice cores on April 25, May 21, June 18, July 27, August 29, October 2, November 1, November 18, and November 30.

In March 2006, when ice allowed safe travel only adjacent to the shore, sea ice thickness was measured every 5 days at 3 to 5 holes, drilled with a $0.05 \mathrm{~m}$ diameter stainless steel auger. The accuracy of the drill hole method was $\pm 0.005 \mathrm{~m}$ [21]. From late March to late December 2006 the ice thickness was measured every $2-5$ days using the drill hole method at a distance of $1 \mathrm{~m}$ around the initial measurement sites. The fitting thickness functions for the period are $h(t)=0.7822+$ 
$8.0 \times 10^{-8} t$. The pure ice density, heat capacity, and thermal conductivity are related to temperature and pressure. The parameters values in QTS are given in Table 1.

4.2. Results and Discussions. Using the observed temperature data from June 21 to July 15 and the salinity observations, we get the results of identified parameters shown in Table 2. Figures 2 and 3 present the salinity distributions. Figure 2 gives the mean salinity distributions at the normalized-depth and Figure 4 shows nine salinity profiles at the ice depth on April 25, May 21, June 18, July 27, August 29, October 2, November 1 , November 18, and November 30 . The salinity unit is in parts per thousand (ppt), that is, the mass of salt in grams per kilogram of sea ice, where the red curves are salinity profiles for PIM, the blue for Eicken, and the green for THESCI. The black dots are observations. The gray lines in Figure 2 are the ranges for the measurement errors. Figure 4 shows the absolute errors for the ice salinity profiles on the nine days. Figure 5 presents the absolute errors and Figure 6 gives the defined temperature error configurations. To examine the validity, we make another simulation for temperature profiles from May 27 to June 20. The defined salinity and temperature errors are presented in Tables 2 and 3. Figure 7 presents the absolute errors and Figure 8 gives the defined temperature errors for the simulated temperature profiles.

In Figure 2, the mean salinity distribution for PIM is shaped like a question mark with low, high, low, and high salinities as seen from the top. This is uniform with the observations and [21]. Compared to the salinity observations in Figure 3, there are 28 points for PIM in the range of measurement errors, 23 for Eicken, and 18 for THESCI. This means that, among the three results, PIM is the best.

In Figure 3, as seen from the top, the shape observed in the first subgraph is shaped like a question mark with low, high, low, and high salinities. But it does not happen for the three numerical results. This is because the three are shaped with high, low, low, and high salinities. Compared with Eicken and THESCI, the top salinity for PIM is much closer to the observation. Except for the first subgraph in Figure 4, vertical salinity distributions for PIM show typical "question-mark-shaped" profiles.

In Figure 4, the smallest deviation to the observations for PIM is the top point on November 1 and the largest is the bottom point on November 18. From Figure 5, we can conclude that 40 absolute errors for PIM are the smallest among the three results, 32 for Eicken, and 18 for THESCI.

Since we take the ice depth $0.36 \mathrm{~m}$ and $0.66 \mathrm{~m}$ as the upper and lower boundaries for the thermodynamic system QTS in Figure 5 and $0.12 \mathrm{~m}$ and $0.78 \mathrm{~m}$ in Figure 7 , the absolute temperature errors in the first and last subgraphs are zero. The error fluctuations to zero for PIM at the remainder six depths in Figure 5 and at the remainder eight depths in Figure 7 are shown. Most absolute errors for PIM are smaller.

In Figures 6 and 8, most errors of the defined temperature for PIM are smaller than those for Eicken.

From Tables 2 and 3, we can get that the errors for PIM are less than those for Eicken and THESCI.
From these tables and figures, we can conclude that the numerical results using PIM correspond to the actual characteristics of the ice salinity and temperature distributions and approach the field data better than those using Eicken's and THESCI's parameters. The parameter identification method is effective when field data are spare and unsatisfactory due to the difficulties associated with fieldwork, especially during the polar winter. Thus the mean salinity function can be applied and our method is valid, and the method can help in interpreting field data and can be used to overcome data gaps.

\section{Conclusions and Further Work}

In this paper, we aim to provide a new method to estimate the salinity of sea ice neglecting the influence of snow and ocean on ice. We have gotten the parameter values describing the salinity and operated another numerical simulation during different measurement periods. Compared with the results of Eicken's and THESCI's, the numerical results of the new method indicate that not only the method is valid, but also our model with the optimal parameters can be used, for example, to overcome data gaps.

However, currently the impact of snow on sea ice, of the oceanic heat flux, and of radiation penetrating through snow on top of the sea ice is not included in our mathematical framework. Additionally, we do not account for the impact of brine moving within sea ice on the temperature field. These limitations will be the subject of the future work.

\section{Conflict of Interests}

The authors declare that there is no conflict of interests regarding the publication of this paper.

\section{Acknowledgments}

This work was supported by the National Natural Science Foundation of China under Grant nos. 11101262, 11171050, and U1232112, Dalian University of Technology Special Fund under Grant no. DUTTX2011106, Key Disciplines of Shanghai Municipality under Grant no. S30104, and a grant of "The First-Class Discipline of Universities in Shanghai." The authors are grateful to all the 2006 winter-over crews at Zhongshan Station in the 22nd CHINARE for their field work support.

\section{References}

[1] G. A. Maykut and N. Untersteiner, "Some results from a timedependent thermodynamic model of sea ice," Journal of Geophysical Research, vol. 76, no. 6, pp. 1550-1575, 1971.

[2] M. C. Serreze, M. M. Holland, and J. Stroeve, "Perspectives on the Arctic's shrinking sea-ice cover," Science, vol. 315, no. 5818, pp. 1533-1536, 2007.

[3] E. C. Carmack, "Circulation and mixing in ice-covered waters," in The Geophysics of Sea Ice, N. Untersteiner and M. Nijhoff, Eds., vol. 146 of Nato ASI Series B, pp. 641-712, Springer, Dordrecht, The Netherland, 1986. 
[4] M. Vancoppenolle, T. Fichefet, and H. Goosse, "Simulating the mass balance and salinity of Arctic and Antarctic sea ice. 2. Importance of sea ice salinity variations," Ocean Modelling, vol. 27, no. 1-2, pp. 54-69, 2009.

[5] E. C. Hunke, D. Notz, A. K. Turner, and M. Vancoppenolle, "The multiphase physics of sea ice: a review for model developers," The Cryosphere, vol. 5, no. 4, pp. 989-1009, 2011.

[6] F. Malmgren, "On the properties of sea ice, The Norwegian North Polar Expedition with the "Maud" 1918-1925," John Griega Bokst, vol. 1, no. 5, pp. 1-67, 1927.

[7] W. Schwarzacher, "Pack-ice studies in the Arctic Ocean," Journal of Geophysical Research, vol. 64, pp. 2357-2367, 1954.

[8] H. Eicken, "Salinity profiles of Antarctic sea ice: field data and model results," Journal of Geophysical Research, vol. 97, no. C10, pp. 15545-15557, 1992.

[9] M. Vancoppenolle, T. Fichefet, and C. M. Bitz, "Modeling the salinity profile of undeformed Arctic sea ice," Geophysical Research Letters, vol. 33, no. 21, Article ID L21501, 2006.

[10] A. J. Gough, A. R. Mahoney, P. J. Langhorne, M. J. M. Williams, and T. G. Haskell, "Sea ice salinity and structure: a winter time series of salinity and its distribution," Journal of Geophysical Research C: Oceans, vol. 117, no. 3, Article ID C03008, 2012.

[11] S. Omatu and J. H. Seinfeld, Distributed Parameter Systems, Clarendon Press, Oxford, UK, 1989.

[12] L. Li, Y. Yang, H. Peng, and X. Wang, "Parameters identification of chaotic systems via chaotic ant swarm," Chaos, Solitons and Fractals, vol. 28, no. 5, pp. 1204-1211, 2006.

[13] H. Peng, L. Li, Y. Yang, and F. Liu, "Parameter estimation of dynamical systems via a chaotic ant swarm," Physical Review E: Statistical, Nonlinear, and Soft Matter Physics, vol. 81, no. 1, Article ID 016207, 2010.

[14] L. Li, Y. Yang, and H. Peng, "Fuzzy system identification via chaotic ant swarm," Chaos, Solitons and Fractals, vol. 41, no. 1, pp. 401-409, 2009.

[15] E. Ozbilge and A. Demir, "Identification of the unknown coefficient in a quasi-linear parabolic equation by a semigroup approach," Journal of Inequalities and Applications, vol. 2013, article 212, 7 pages, 2013.

[16] W. Lv, E. Feng, and Z. Li, "A coupled thermodynamic system of sea ice and its parameter identification," Applied Mathematical Modelling. Simulation and Computation for Engineering and Environmental Systems, vol. 32, no. 7, pp. 1198-1207, 2008.

[17] W. Lv, E. Feng, and Z. Li, "Properties and optimality conditions of a three-dimension non-smooth thermodynamic system of sea ice," Applied Mathematical Modelling, vol. 33, no. 5, pp. 23242333, 2009.

[18] W. Lv, E. Feng, and R. Lei, "Parameter identification for a nonlinear non-smooth thermodynamic system of sea ice," International Journal of Thermal Sciences, vol. 48, no. 1, pp. 195203, 2009.

[19] E. E. Ebert and J. A. Curry, "An intermediate one-dimensional thermodynamic sea ice model for investigating ice-atmosphere interactions," Journal of Geophysical Research, vol. 98, no. 6, pp. 10085-10109, 1993.

[20] O. A. Ladyzenskaja, V. A. Solonnikov, and N. N. Ural'ceva, Linear and Quasilinear Equations of Parabolic Type, American Mathematical Society, Providence, RI, USA, 1968.

[21] R. Lei, Z. Li, B. Cheng, Z. Zhang, and P. Heil, "Annual cycle of landfast sea ice in Prydz Bay, east Antarctica," Journal of Geophysical Research C: Oceans, vol. 115, no. 2, Article ID C02006, 2010. 


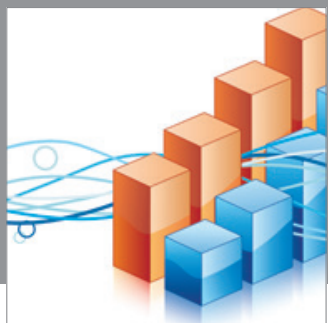

Advances in

Operations Research

mansans

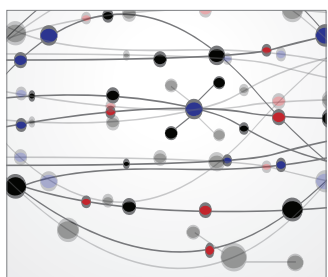

The Scientific World Journal
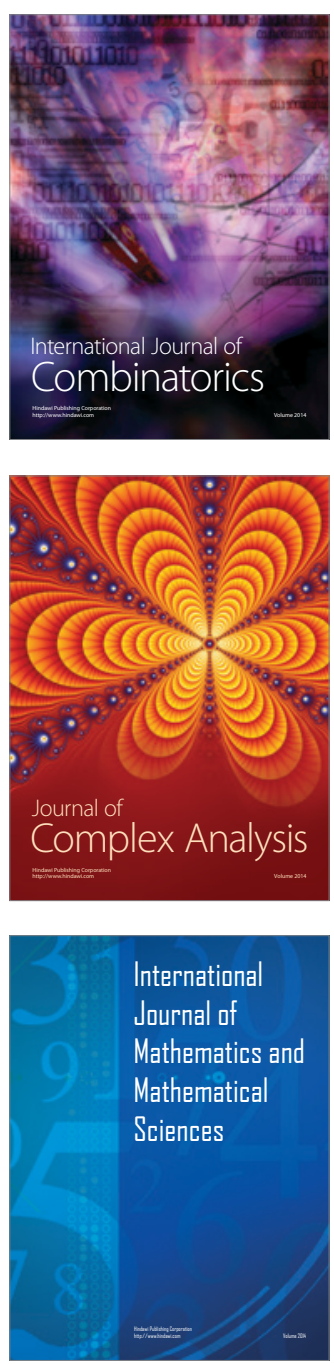
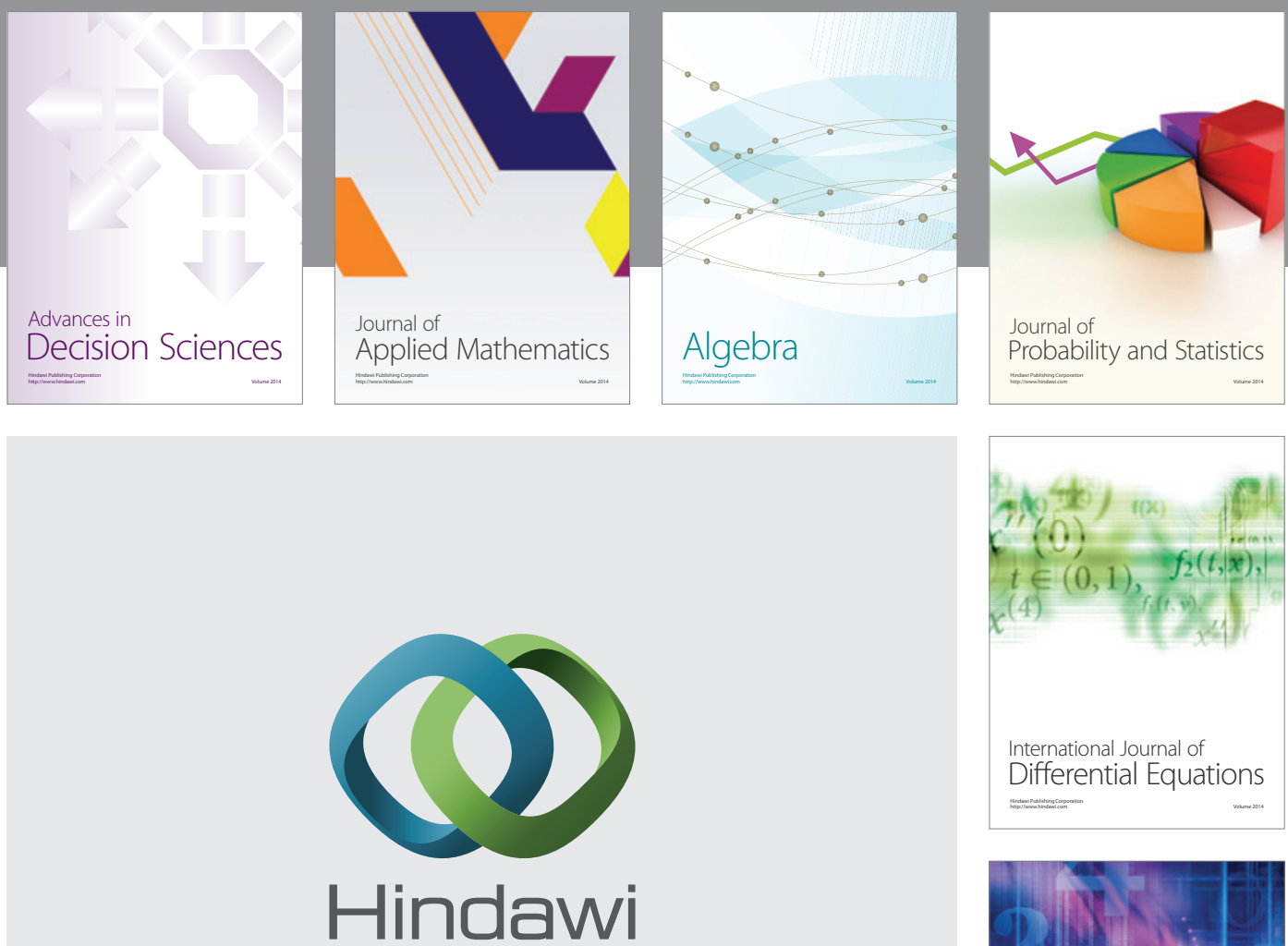

Submit your manuscripts at http://www.hindawi.com
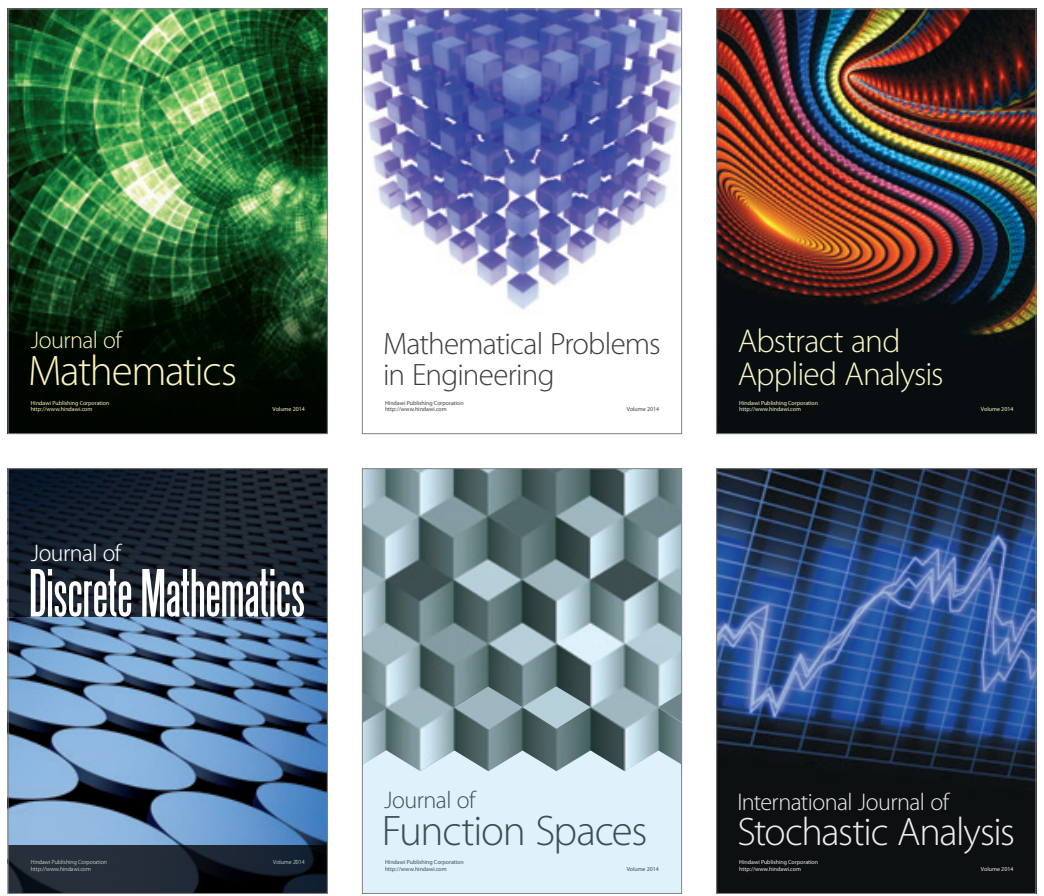

Journal of

Function Spaces

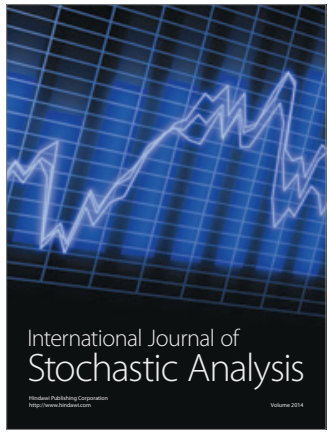

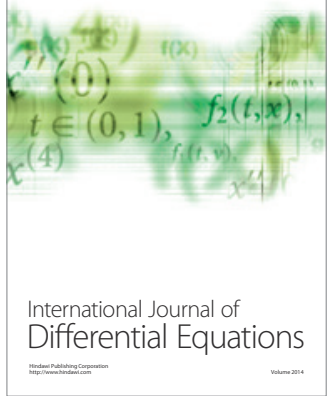
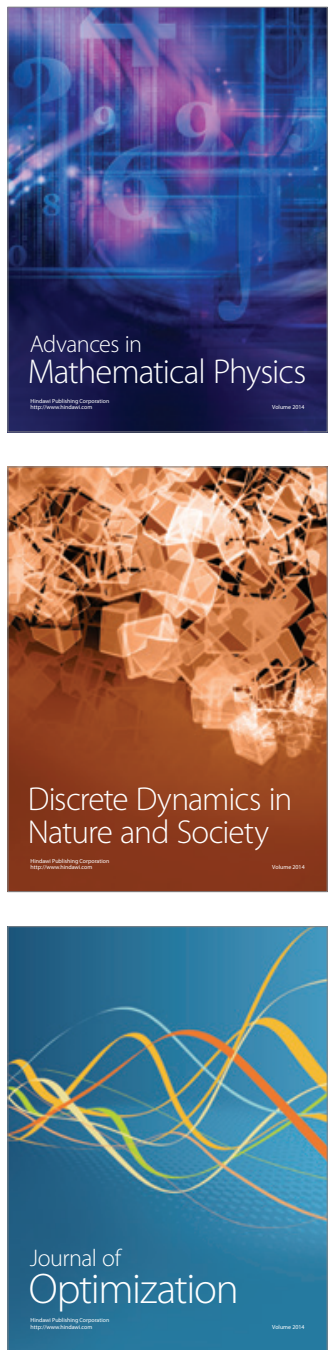